\title{
Effects of heme oxygenase-1 recombinant Lactococcus lactis on the intestinal barrier of hemorrhagic shock rats
}

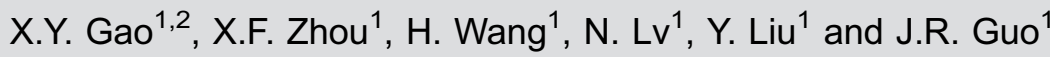 \\ ${ }^{1}$ Department of Anesthesiology, Gongli Hospital, Second Military Medical University, Shanghai, China \\ ${ }^{2}$ Shool of Medicine, Shandong University, Shandong, China
}

\begin{abstract}
This study aimed to investigate the effects of heme oxygenase-1 recombinant Lactococcus lactis (LL-HO-1) on the intestinal barrier of rats with hemorrhagic shock. One hundred Sprague-Dawley male rats (280-320 g) were randomly divided into healthy control group ( $\mathrm{N}$ group) and hemorrhagic shock group (H group). Each group was subdivided into HO1t, HO2t, HO3t, PBS and LL groups in which rats were intragastrically injected with LL-HO-1 once, twice and three times, PBS and L. lactis (LL), respectively. The mortality, intestinal myeloperoxidase (MPO) activity, intestinal contents of TNF- $\alpha$, IL-10 and HO-1, and intestinal Chiu's score were determined. Results showed that in N group, the HO-1 content increased after LL-HO-1 treatment, and significant difference was observed in HO1t group and HO2t group $(\mathrm{P}<0.05)$. In $\mathrm{H}$ groups, MPO activity and Chiu's score decreased, but IL-10 content increased in LL-HO-1-treated groups when compared with PBS and LL groups $(\mathrm{P}<0.05)$. When compared with $\mathrm{N}$ group, the MPO activity reduced dramatically in LL-HO-1-treated groups. Thus, in healthy rats ( $\mathrm{N}$ group), intragastrical LL-HO-1 treatment may increase the intestinal HO-1 expression, but has no influence on the intestinal barrier. In hemorrhagic shock rats, LL-HO-1 may significantly protect the intestinal barrier, and repeating the intragastrical LL-HO-1 treatments twice has the most obvious protection.
\end{abstract}

Key words: Heme oxygenase-1; Hemorrhagic shock; Lactococcus lactis; Intestinal barrier; Intestinal inflammation

\section{Introduction}

Hemorrhagic shock (HS) is a common complication of patients with severe trauma in clinical practice, and mortality is about $30-40 \%(1,2)$. In HS, the intestine is the first organ affected by the ischemia/reperfusion injury. Mucosal edema and villus rupture may be observed histopathologically. Bacteria from the intestines may enter blood circulation via the ruptured intestine (also known as bacterial translocation). The activities of macrophages and other immune cells increase, and the neutrophils are activated, resulting in damages to other organs and tissues (3-5). Heme oxygenase-1 ( $\mathrm{HO}-1)$ is also known as heat shock protein 32 (HSP32) and is a member of heat shock protein (HSP) family. HO-1 is an important and unique inducible $\mathrm{HO}$ and can degrade the free heme released by aging or damaged red blood cells to produce carbon monoxide (CO), biliverdin (which will be further oxidized into bilirubin in the intestine) and divalent iron $\left(\mathrm{Fe}^{2+}\right) . \mathrm{HO}-1$ itself and its catalyst have anti-oxidative activities in the body. Evidence has confirmed that $\mathrm{HO}-1$ is protective against $\mathrm{HS}$ via its anti-inflammation, anti-apoptosis, regulation of cell cycle, and maintenance of microcirculation (6-8).
In our lab, recombinant Lactococcus lactis expressing HO-1 (LL-HO-1) were successfully constructed by genetic engineering. Our previous study has confirmed that the bacteria may enter the ileum in healthy rats after intragastrical administration of LL-HO-1 at a certain dose. In the presence of $\mathrm{HS}$ and/or endotoxemia, $\mathrm{HO}-1$ expression increased after LL-HO-1 treatment, which may protect the intestinal barrier via attenuating the intestinal inflammation (9-13). However, whether the number of intragastrical $\mathrm{LL}-\mathrm{HO}-1$ treatments affect the protection of LL-HO-1 on the intestinal barrier is still unclear. In the present study, the intestinal barrier was evaluated in healthy rats and HS rats after repeated intragastrical LL-HO-1 treatments.

\section{Material and Methods}

\section{Grouping and procedures}

One hundred male Sprague-Dawley rats weighing 280$320 \mathrm{~g}$ were purchased from the Experimental Animal Center of Xuzhou Medical Collage. The protocol was approved by the Ethics Committee of Xuzhou Medical Collage,

Correspondence: J.R. Guo: <guojianrong_sh@163.com> 
China. Rats were randomly assigned into healthy control group ( $\mathrm{N}$ group, $\mathrm{n}=50$ ) and hemorrhagic shock group ( $\mathrm{H}$ group, $\mathrm{n}=50$ ). Each group was further subdivided into 5 subgroups ( $n=10$ per group): 1) one administration of LL-HO-1 (HO1t), 2) two administrations of LL-HO-1 (HO2t), $3)$ three administrations of LL-HO-1 (HO3t), 4) phosphatebuffered saline (PBS) group, and 5) $L$. lactis treatment group (LL). The time interval between treatments was $24 \mathrm{~h}$, and $1 \mathrm{~mL}$ of the solution was administered intragastrically. In the HO1t, HO2t, HO3t, and LL groups, $2.5 \times 10^{9} \mathrm{CFU} / \mathrm{mL}$ bacteria was administered. In PBS group, $1 \mathrm{~mL}$ of PBS was administered intragastrically. All animals received food deprivation before the experiment, but were given ad libitum access to food and water after.

At $24 \mathrm{~h}$ after the last intragastrical treatment, HS was induced in the $\mathrm{H}$ groups. In brief, rats were anesthetized and fixed in a supine position. Under an aseptic condition, the right femoral artery and the left femoral vein were separated. Bloodletting was done via the femoral artery, and the mean arterial pressure (MAP) was maintained at $35-40 \mathrm{mmHg}$ for $60 \mathrm{~min}$. Then, the collected blood and Ringer's lactate solution (1:2) were infused via the femoral vein within $30 \mathrm{~min}$, and the blood pressure was maintained at $\geqslant 90 \%$ of that before the experiment, suggesting the successful resuscitation.

Animals were anesthetized with chloral hydrate at $1 \mathrm{~h}$ after $\mathrm{HS}$ in $\mathrm{H}$ group and at $24 \mathrm{~h}$ after the last intragastrical treatment in control group. Laparotomy was performed under an aseptic condition, and a 5-cm ileum was collected at the ileum terminal for further examinations. The mortality, intestinal myeloperoxidase (MPO) activity, and intestinal contents of TNF- $\alpha, \mathrm{IL}-10$ and $\mathrm{HO}-1$ were determined. Colorimetry was used to determine the MPO activity (14), using a specific testing kit (Nanjing Jiancheng Bioengineering Institute, China) according to the manufacturer's protocols. The results of the MPO activity are reported as U/mg protein. In brief, $50 \mathrm{mg}$ of small intestine tissue was weighed accurately and slurried with $950 \mu \mathrm{L}$ medium. Reagent III $(0.1 \mathrm{~mL})$ was added to $0.9 \mathrm{~mL}$ homogenate and put in a $37^{\circ} \mathrm{C}$ water bath for $15 \mathrm{~min}$. A $0.2 \mathrm{~mL}$ sample was added in the testing tube and in the control tube. The color-developing agent was added to the testing tube while distilled water was added to the control tube. Tubes were mixed and put in a $37^{\circ} \mathrm{C}$ water bath for $30 \mathrm{~min}$. Then, reagent VII was added to each tube, mixed and put in a $37^{\circ} \mathrm{C}$ water bath of for $60 \mathrm{~min}$. The absorbance level was measured immediately at $460 \mathrm{~nm}$ and $1 \mathrm{~cm}$ light path. MPO activity was measured with different absorbance levels. Immunohistochemistry followed by RichWin97 Software (Media Cybernetics, USA) were used to analyze the intestinal contents of TNF- $\alpha$, IL-10 and HO-1. Ten areas of one field $\left({ }^{*} 100\right)$ were chosen to calculate the gray value.

Histological examination was performed under a light microscope by experienced pathologists blind to the grouping in this study. Chiu's 6-point scoring system was employed to evaluate the intestinal mucosal injury, as follows: 0 , normal; 1 , enlargement of sub-epithelial space at the villus top; 2 , moderate separation between epithelium and lamina propria; 3 , significantly separated villi with destruction of the villus top; 4 , destruction of the villus and exposure of capillaries in the lamina propria; 5 , destruction, hemorrhage and ulcer in the lamina propria.

\section{Statistical analysis}

Quantitative data are reported as means \pm SD. Intragroup comparisons were done with $t$-test, and intergroup comparisons with one-way analysis of variance. Statistical analysis was performed with SPSS version 19.5 (USA). $A$ value of $P<0.05$ was considered to be statistically significant.

\section{Results}

\section{Mortality}

In $\mathrm{H}-\mathrm{HO} 1 \mathrm{t}, \mathrm{H}-\mathrm{HO} 2 \mathrm{t}$ and $\mathrm{H}-\mathrm{HO} 3 t$ groups, no animal died within $1 \mathrm{~h}$ after HS. However, in H-PBS and $\mathrm{H}$-LL groups, 2 died before sample collection (mortality of $20 \%$ ). In the control group, none died during the study. As shown in Figure 1, when compared with H-PBS and H-LL groups, the mortality was reduced significantly in the remaining groups $(\mathrm{P}<0.05)$.

\section{MPO activity of the intestine}

As shown in Figure 2, the intestinal MPO activity in $\mathrm{H}-\mathrm{PBS}$ and $\mathrm{H}-\mathrm{LL}$ groups increased dramatically when compared with N-PBS and N-LL groups $(\mathrm{P}<0.05)$. MPO activity in $\mathrm{H}-\mathrm{HO} 1 \mathrm{t}, \mathrm{H}-\mathrm{HO} 2 \mathrm{t}$ and $\mathrm{H}-\mathrm{HO} 3 t$ groups reduced significantly when compared with $\mathrm{H}-\mathrm{LL}$ and $\mathrm{H}-\mathrm{PBS}$ groups $(\mathrm{P}<0.05)$. MPO activity in $\mathrm{H}-\mathrm{HO} 1 \mathrm{t}$ and $\mathrm{H}-\mathrm{HO} 2 \mathrm{t}$ groups reduced significantly when compared with $\mathrm{H}-\mathrm{HO} 3 t$ group $(\mathrm{P}<0.05)$. MPO activity in $\mathrm{H}-\mathrm{HO} 1 \mathrm{t}, \mathrm{H}-\mathrm{HO} 2 \mathrm{t}$ and $\mathrm{H}-\mathrm{HO} 3 \mathrm{t}$ groups reduced significantly when compared with $\mathrm{N}-\mathrm{HO} 1 \mathrm{t}$, $\mathrm{N}-\mathrm{HO} 2 \mathrm{t}$ and $\mathrm{N}-\mathrm{HO} 3 t$ groups, respectively $(\mathrm{P}<0.05)$.

\section{Contents of TNF- $\alpha$, IL-10 and HO-1 in the intestines}

As shown in Figure 3, when compared with H-PBS and H-LL groups, the intestinal IL-10 content in $\mathrm{H}-\mathrm{HO} 1 \mathrm{t}$,

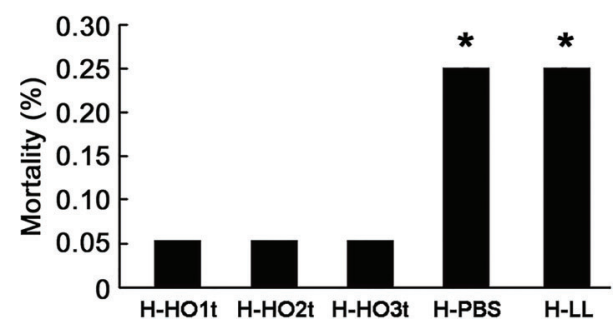

Figure 1. Mortality in hemorrhagic shock ( $\mathrm{H}$ groups) treated once with Lactococcus lactis expressing heme oxygenase-1 ( $\mathrm{H}-\mathrm{HO} 1 \mathrm{t})$, twice $(\mathrm{H}-\mathrm{HO} 2 \mathrm{t})$, three times $(\mathrm{H}-\mathrm{HO} 3 \mathrm{t})$ or treated with phosphatebuffered saline (PBS) and $L$. lactis $(\mathrm{LL}){ }^{*} \mathrm{P}<0.05$ : compared to the remaining groups (ANOVA). 


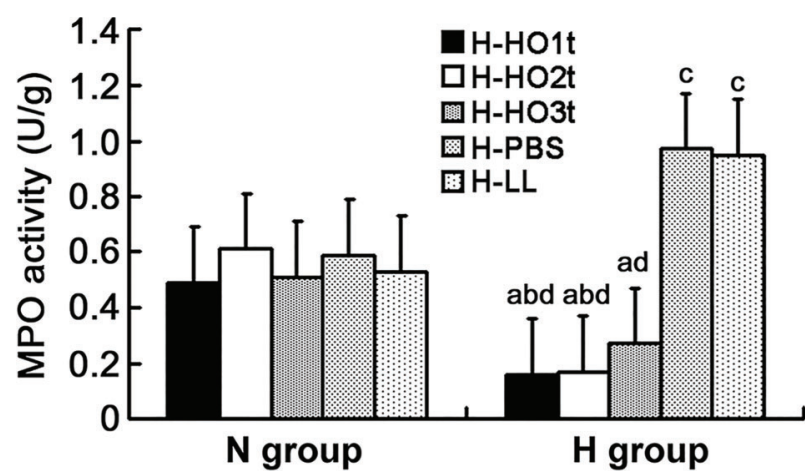

Figure 2. Myeloperoxidase (MPO) activity in normal (N) groups and hemorrhagic shock $(\mathrm{H})$ groups treated with Lactococcus lactis expressing heme oxygenase- 1 once $(\mathrm{HO} 1 \mathrm{t})$, twice $(\mathrm{HO} 2 \mathrm{t})$ or thrice (HO3t) or with phosphate-buffered saline (PBS) and L. lactis (LL). ${ }^{\mathrm{a}} \mathrm{P}<0.05$, compared with $\mathrm{H}-\mathrm{PBS}$ and $\mathrm{H}-\mathrm{LL}$; ${ }^{\mathrm{b}} \mathrm{P}<0.05$, compared with $\mathrm{H}-\mathrm{HO} 3$; ${ }^{\mathrm{C}} \mathrm{P}<0.05$, compared with $\mathrm{N}$; ${ }^{\mathrm{d}} \mathrm{P}<0.05$, compared with $\mathrm{N}$ group (ANOVA). Data are reported as means \pm SD.

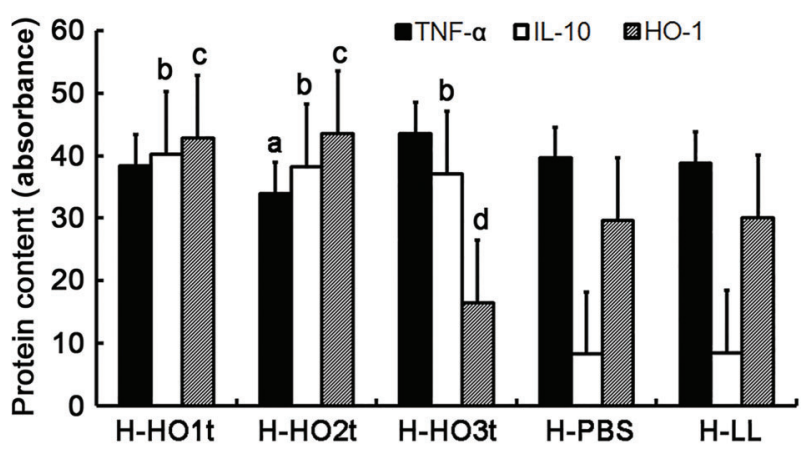

Figure 3. Levels of TNF- $\alpha$, IL-10 and heme oxygenase-1 (HO-1) in the intestine of hemorrhagic shock (HS) rat groups treated with Lactococcus lactis expressing heme oxygenase-1 once ( $\mathrm{HO} 1 \mathrm{t})$, twice $(\mathrm{HO} 2 \mathrm{t})$ or thrice $(\mathrm{HO} 3 \mathrm{t})$ or with phosphate-buffered saline (PBS) and $L$. lactis (LL). ${ }^{\text {abc }} \mathrm{P}<0.05$ : compared with the corresponding PBS and LL groups (ANOVA). Data are reported as means $\pm S D$.

$\mathrm{H}-\mathrm{HO} 2 \mathrm{t}$ and $\mathrm{H}-\mathrm{HO} 3 t$ groups increased significantly, TNF- $\alpha$ content in $\mathrm{H}-\mathrm{HO} 2 \mathrm{t}$ group reduced, $\mathrm{HO}-1$ content in $\mathrm{H}-\mathrm{HO} 1 \mathrm{t}$ and $\mathrm{H}-\mathrm{HO} 2 \mathrm{t}$ groups increased, but $\mathrm{H}-\mathrm{HO}-1$ content reduced significantly in $\mathrm{H}-\mathrm{HO} 3 t$ group $(\mathrm{P}<0.05)$.

\section{HO-1 content in control groups}

As shown in Figure 4, when compared with N-PBS and $\mathrm{N}$-LL groups, the $\mathrm{HO}-1$ content in $\mathrm{N}-\mathrm{HO} 1 \mathrm{t}, \mathrm{N}-\mathrm{HO} 2 \mathrm{t}$ and $\mathrm{N}-\mathrm{HO} 3 \mathrm{t}$ groups increased, and a significant difference was observed between $\mathrm{N}-\mathrm{HO} 1 \mathrm{t}$ group and $\mathrm{N}-\mathrm{HO} 2 \mathrm{t}$ group $(P<0.05)$.

\section{Chiu's scores}

As shown in Figures 5 and 6, the morphology of the intestine was normal, and further comparisons were not

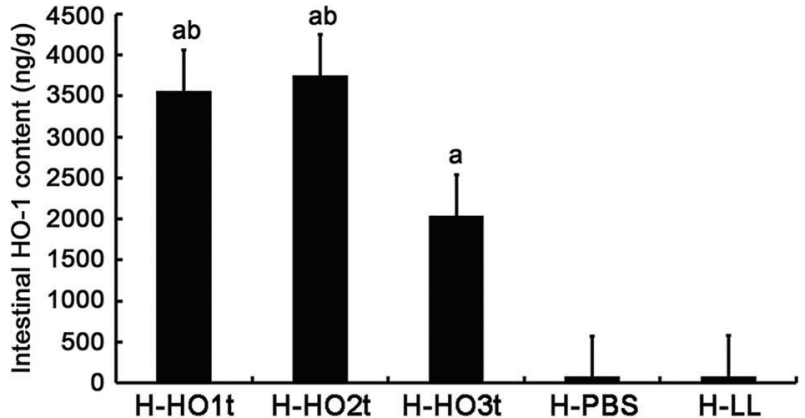

Figure 4. Content of heme oxygenase-1 (HO-1) in the intestine of different $\mathrm{N}$ groups treated with Lactococcus lactis expressing heme oxygenase-1 once ( $\mathrm{HO} 1 \mathrm{t})$, twice $(\mathrm{HO} 2 \mathrm{t})$ or thrice $(\mathrm{HO} 3 \mathrm{t})$ or with phosphate-buffered saline (PBS) and L. lactis (LL) (ng/g). ${ }^{\mathrm{a} P}<0.05$ : compared with PBS and LL groups; ${ }^{\mathrm{b}} \mathrm{P}<0.05$ : compared with $\mathrm{HO}$ t group (ANOVA). Data are reported as means \pm SD.

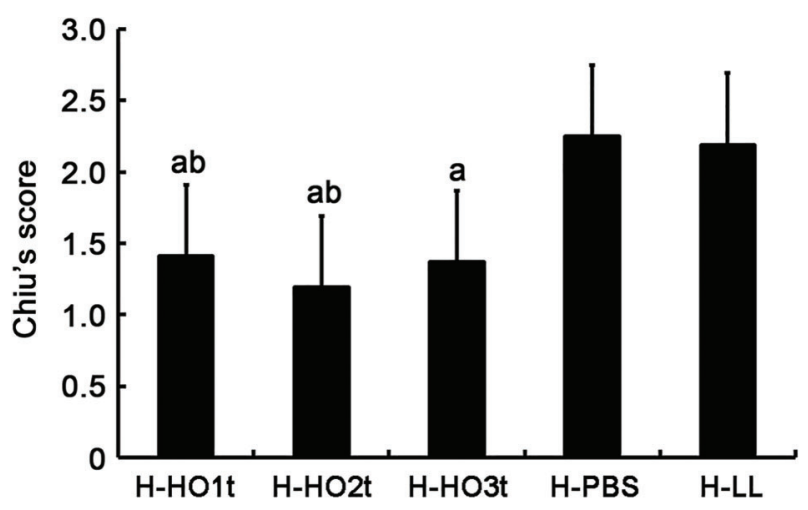

Figure 5. Chiu's score of hemorrhagic shock $(\mathrm{H})$ rats treated with Lactococcus lactis expressing heme oxygenase-1 once ( $\mathrm{HO} 1 \mathrm{t})$, twice $(\mathrm{HO} 2 \mathrm{t})$ or thrice $(\mathrm{HO} 3 \mathrm{t})$ or with phosphate-buffered saline (PBS) and $L$. lactis (LL). ${ }^{\text {aP }}<0.05$ : compared with PBS and LL; ${ }^{\mathrm{b}} \mathrm{P}<0.05$ : compared with $\mathrm{HO} 1 \mathrm{t}$ and $\mathrm{H}-\mathrm{HO}$ t (ANOVA). Data are reported as means \pm SD.

performed in the $\mathrm{N}$ groups. When compared with H-PBS and $\mathrm{H}-\mathrm{LL}$ groups, the Chiu's score reduced significantly in $\mathrm{H}-\mathrm{HO} 1 \mathrm{t}, \mathrm{H}-\mathrm{HO} 2 \mathrm{t}$ and $\mathrm{H}-\mathrm{HO} 3 \mathrm{t}$ groups; when compared with $\mathrm{H}-\mathrm{HO} 1 \mathrm{t}$ and $\mathrm{H}-\mathrm{HO} 3$ t groups, the Chiu's score reduced significantly $(\mathrm{P}<0.05)$ in $\mathrm{H}-\mathrm{HO} 2 \mathrm{t}$ group.

\section{Discussion}

A large number of studies confirm that the intestinal barrier is the first to be damaged following HS and other situations of low blood perfusion, presenting pathological changes (4). The ischemia/reperfusion and neutrophil (PMN) activation due to HS may cause the release of preinflammatory cytokines and the production of a variety of reactive oxygen species, which may lead to systemic inflammatory response syndrome, resulting in organ dysfunction and damage to cells and tissues $(15,16)$. Under normal 

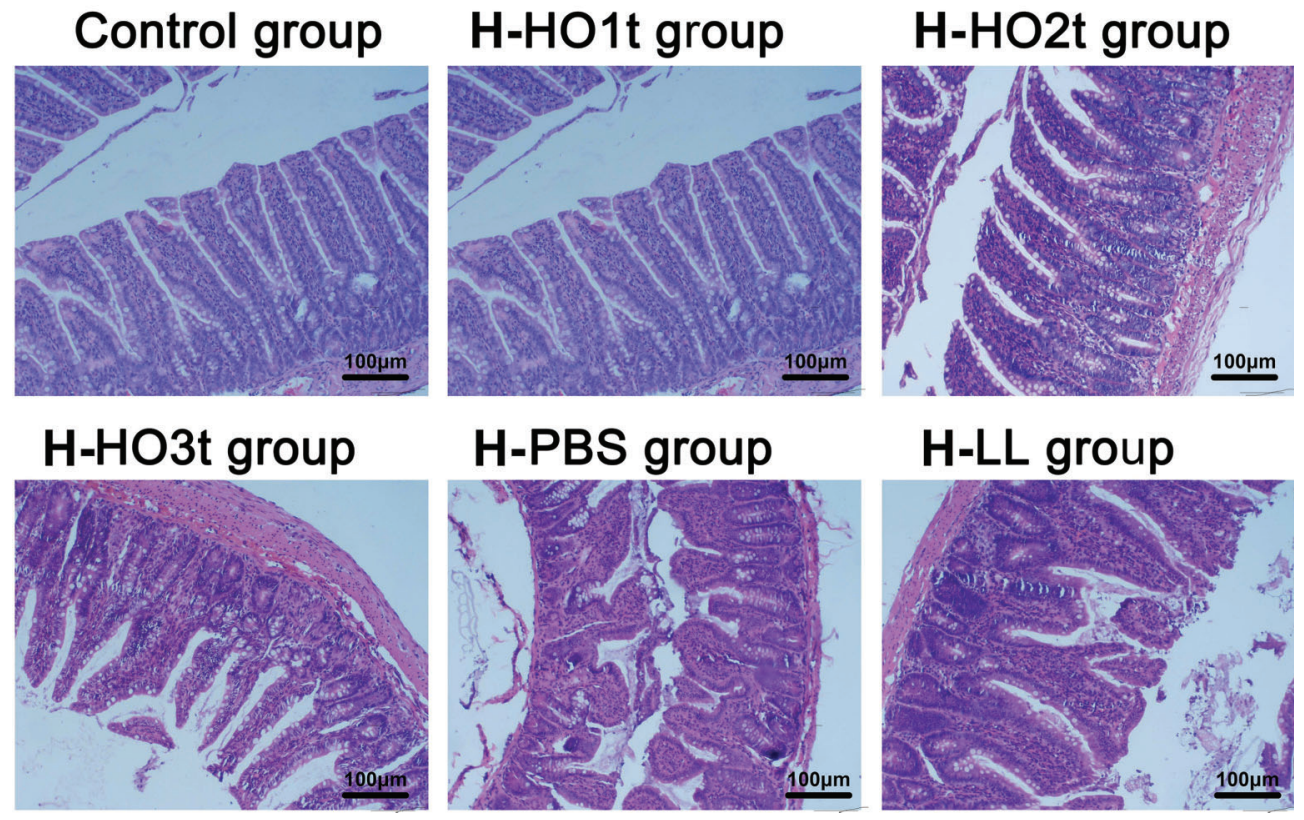

Figure 6. Pathological examination of intestinal tissue of hemorrhagic shock $(\mathrm{H})$ groups treated with Lactococcus lactis expressing heme oxygenase-1 once $(\mathrm{HO} 1 \mathrm{t})$, twice $(\mathrm{HO} 2 \mathrm{t})$ or thrice $(\mathrm{HO} 3 \mathrm{t})$ or with phosphate-buffered saline (PBS) and L. lactis (LL). Control group refers to healthy rats (HE staining; $\times 100)$.

conditions, intestinal epithelial cells form a potent barrier via intercellular connections and adhesion, which protect the intestine against injury (17). In the presence of inflammation, a large amount of activated PMNs may exert mechanical effects via their pseudopodia and release reactive oxygen species, causing damage to the intestinal barrier, mucosal edema and intestinal barrier dysfunction, which is an important mechanism of intestinal inflammation. Activated PMN may release MPO, which activity reflects the number of PMN (18). Chiu's score, which is a morphological parameter reflecting the intestinal function (19), was used to evaluate the intestinal mucosal injury. The intestine is a major TNF- $\alpha$-secreting organ and a major source of TNF- $\alpha$ in HS (20). IL-10 is the most important anti-inflammatory cytokine in the intestinal immune system. IL-10 may inhibit immune function and down-regulate inflammation, and thus has been a key maker of anti-inflammation in the intestine (21). The anti-inflammatory effect of IL-10 is mediated by $\mathrm{HO}-1$, and one may induce the expression of the other, forming a positive feedback in the anti-inflammatory process (22). Regulating the secretion of the $\mathrm{HO}$ family members (HO-1, $\mathrm{HO}-2$ and $\mathrm{HO}-3$ ) is a promising way of protecting against injury. For example, inducing the expression of free $\mathrm{HO}-1$ exerts anti-oxidative effects and protects the organs against damage (23). Thus, $\mathrm{HO}-1$ has become an important anti-oxidant in human body $(8,24,25)$.

In the present study, the MPO activity and Chiu's scores in control groups were comparable, suggesting that intragastric LL-HO-1 treatment has no influence on the immune function of the intestine and does not disrupt the intestinal barrier. Thus, the TNF- $\alpha$ and IL-10 contents were not measured in control groups. In H-PBS and $\mathrm{H}-\mathrm{LL}$ groups, the MPO activity and Chiu's scores were significantly higher than in control group, which is related to the compromised intestinal barrier and intestinal inflammation following stress. MPO activity in $\mathrm{H}-\mathrm{HO} 1 \mathrm{t}, \mathrm{H}-\mathrm{HO} 2 \mathrm{t}$ and $\mathrm{H}-\mathrm{HO} 3 \mathrm{t}$ groups was markedly lower than in control groups, which is associated with $\mathrm{HO}-1$-induced reduction in intestinal stress (decrease in PMN activation and inhibition of intestinal inflammation). However, when compared with $\mathrm{H}-\mathrm{HO} 1 \mathrm{t}$ and $\mathrm{H}-\mathrm{HO} 3 \mathrm{t}$ groups, the protective effects were better in $\mathrm{H}-\mathrm{HO} 2 \mathrm{t}$ group, suggesting the improvement of intestinal inflammation and better intestinal barrier.

The TNF- $\alpha$ content was comparable in $\mathrm{H}$ groups, indicating similar stress levels. However, the contents of $\mathrm{IL}-10$ and $\mathrm{HO}-1$ in $\mathrm{H}-\mathrm{HO} 1 \mathrm{t}, \mathrm{H}-\mathrm{HO} 2 \mathrm{t}$ and $\mathrm{H}-\mathrm{HO} 3 t$ groups were significantly higher than in control group, suggesting that the anti-inflammatory cytokine increases, which is helpful for the anti-inflammatory effects in late stages. In this study, the inflammatory cytokine was assessed only within $1 \mathrm{~h}$ after HS, which was one of limitations of this study.

In this study, LL-HO-1-treated rats survived after intragastrical treatment, leading to the increased $\mathrm{HO}-1$ expression in the intestine, but the $\mathrm{HO}-1$ expression did not increase with an increased number of intragastrical treatments. On the contrary, the $\mathrm{HO}-1$ expression reduced 
in the intestine after two intragastrical treatments, which was consistent with the findings in the $\mathrm{H}$ group. Compared to the control and $\mathrm{HS}$ groups, the $\mathrm{HO}-1$ expression increased significantly and the intestinal barrier was better after two LL-HO-1 treatments. This may be explained as follows: Firstly, the lactobacillus expression system used in our study is an international, food-grade NICE system widely used for the construction of $L$. lactis expressing exogenous genes (26). However, the release of target proteins by the recombinant $L$. lactis is relatively limited, and the bacteria cannot sustain releasing the target protein in the intestine. Once the $L$. lactis activity reduces, the synthesis and release of its target protein is also reduced $(27,28)$. Secondly, there is evidence that the $\mathrm{HO}-1$ protection is dependent on the $\mathrm{HO}-1$ expression, and excess $\mathrm{HO}-1$ expression may promote lactate dehydrogenase release and reduce glutathione S-transferase, leading to the disruption of cell integrity (29).

Taken together, intragastrical treatment with LL-HO-1 may induce $\mathrm{HO}-1$ expression in the intestine of healthy

\section{References}

1. Bursa F, Pleva L, Maca J, Sklienka P, Sevcik P. Tissue ischemia microdialysis assessments following severe traumatic haemorrhagic shock: lactate/pyruvate ratio as a new resuscitation end point? BMC Anesthesiol 2014; 14: 118, doi: 10.1186/1471-2253-14-118.

2. Amaral NO, Naves LM, Ferreira-Neto ML, Freiria-Oliveira $\mathrm{AH}$, Colombari E, Rosa DA. Median preoptic nucleus mediates the cardiovascular recovery induced by hypertonic saline in hemorrhagic shock. ScientificWorldJournal 2014; 14: 496121, doi: 10.1155/2014/496121.

3. Zhao B, Fei J, Chen $Y$, Ying $Y L$, Ma L, Song $X Q$, et al. Vitamin $C$ treatment attenuates hemorrhagic shock related multi-organ injuries through the induction of heme oxygenase-1. BMC Complement Altern Med 2014; 14: 442, doi: 10.1186/1472-6882-14-442.

4. Murao Y, Hata M, Ohnishi K, Okuchi K, Nakajima Y, Hiasa Y, et al. Hypertonic saline resuscitation reduces apoptosis and tissue damage of the small intestine in a mouse model of hemorrhagic shock. Shock 2003; 20: 23-28, doi: 10.1097/ 01.shk.0000078832.57685.6c

5. Kao RL, Xu X, Xenocostas A, Parry N, Mele T, Martin CM, et al. Induction of acute lung inflammation in mice with hemorrhagic shock and resuscitation: role of HMGB1. J Inflamm 2014; 11: 30, doi: 10.1186/s12950-014-0030-7.

6. Shen Q, Holloway N, Thimmesch A, Wood JG, Clancy RL, Pierce JD. Ubiquinol decreases hemorrhagic shock/resuscitation-induced microvascular inflammation in rat mesenteric microcirculation. Physiol Rep 2014; 2 pii: e12199, doi: 10.14814/phy2.12199.

7. Zhang Y, Jiang G, Sauler M, Lee PJ. Lung endothelial HO-1 targeting in vivo using lentiviral miRNA regulates apoptosis and autophagy during oxidant injury. Faseb $J$ 2013; 27 : 4041-4058, doi: 10.1096/fj.13-231225.

8. Lu YQ, Gu LH, Huang WD, Mou HZ. Effect of hypertonic saline resuscitation on heme oxygenase-1 mRNA expression rats, and protect the intestinal barrier against HS-induced stress. However, whether there is a threshold of $\mathrm{HO}-1$ expression in the $\mathrm{HO}-1$-induced intestinal protection and whether this treatment is related to the activation of endogenous $\mathrm{HO}-1$ are still unclear and require further study.

In conclusion, intragastrical LL-HO-1 treatment may induce $\mathrm{HO}-1$ expression in the intestine without affecting the intestinal barrier in healthy rats. In HS rats, intragastrical LL-HO-1 treatments, especially twice, can significantly protect the intestinal barrier.

\section{Acknowledgments}

The authors are grateful to Dr. Yang Liu for statistical support and data collection. The study was supported by Outstanding Leaders Training Program of Pudong Health Bureau of Shanghai (PWR12013-03) and funded by Key Disciplines Group Construction Project of Pudong Health Bureau of Shanghai (PWZxq2014-06).

and apoptosis of the intestinal mucosa in a rat model of hemorrhagic shock. Chin Med J 2010; 123: 1453-1458.

9. Pang QF, Ji Y, Bermudez-Humaran LG, Zhou QM, Hu G, Zeng $Y$. Protective effects of a heme oxygenase-1-secreting Lactococcus lactis on mucosal injury induced by hemorrhagic shock in rats. J Surg Res 2009; 153: 39-45, doi: 10.1016/j.jss.2008.03.042.

10. Pang QF, Zhou QM, Zeng S, Dou LD, Ji Y, Zeng YM. Protective effect of heme oxygenase-1 on lung injury induced by erythrocyte instillation in rats. Chin Med J 2008; 121: 1688-1692.

11. Gao XY, Ren CC, Zhang X, Yao YH, Pang QF, Wu CY. [Effects of $L$. lactis recombinant heme oxygenase-1 gene on the intestinal barrier in rats with hemorrhagic shock]. Zhongguo Wei Zhong Bing Ji Jiu Yi Xue 2007; 19: 225-228.

12. Gao $X Y$, Ren $C C$, Zhou Q, Pang QF, Wu CY, Zeng YM. Effects of two fluid resuscitations on the bacterial translocation and inflammatory response of small intestine in rats with hemorrhagic shock. Chin J Traumatol 2007; 10: 109-115.

13. Gao XY, Wu CY, Zhou Q, Pang QF, Zeng YM. [Effects of gavage with Lactococcus lactis recombinant heme oxygenase-1 gene on inflammation of intestine and bacterial translocation in rats with hemorrhagic shock]. Zhongguo Wei Zhong Bing Ji Jiu Yi Xue 2006; 18: 546-550.

14. Zheng XY, Lv YF, Li S, Li Q, Zhang QN, Zhang XT, et al. Recombinant adeno-associated virus carrying thymosin beta4 suppresses experimental colitis in mice. World $J$ Gastroenterol 2017; 23: 242-255, doi: 10.3748/wjg.v23. i2.242.

15. Vitturi DA, Chen CS, Woodcock SR, Salvatore SR, Bonacci G, Koenitzer JR, et al. Modulation of nitro-fatty acid signaling: prostaglandin reductase-1 is a nitroalkene reductase. J Biol Chem 2013; 288: 25626-25637, doi: 10.1074/ jbc.M113.486282. 
16. Pacher $P$, Beckman JS, Liaudet L. Nitric oxide and peroxynitrite in health and disease. Physiol Rev 2007; 87: 315-424, doi: 10.1152/physrev.00029.2006.

17. Ge ZJ, Jiang GJ, Zhao YP, Wang GX, Tan YF. Systemic perfluorohexane attenuates lung injury induced by lipopolysaccharide in rats: the role of heme oxygenase-1. Pharmacol Rep 2010; 62: 170-177, doi: 10.1016/S1734-1140(10) 70254-1.

18. Zhao L, Luo L, Jia W, Xiao J, Huang G, Tian G, et al. Serum diamine oxidase as a hemorrhagic shock biomarker in a rabbit model. PLoS One 2014; 9: e102285, doi: 10.1371/ journal.pone. 0102285 .

19. Chiu CJ, McArdle AH, Brown R, Scott HJ, Gurd FN. Intestinal mucosal lesion in low-flow states. I. A morphological, hemodynamic, and metabolic reappraisal. Arch Surg 1970; 101: 478-483, doi: 10.1001/archsurg.1970.01340280 030009.

20. Grocott MP, Mythen MG, Gan TJ. Perioperative fluid management and clinical outcomes in adults. Anesth Analg 2005; 100: 1093-1106, doi: 10.1213/01.ANE.0000148691. 33690.AC

21. Zurita-Turk M, Del Carmen S, Santos AC, Pereira VB, Cara DC, Leclercq SY, et al. Lactococcus lactis carrying the pValac DNA expression vector coding for IL-10 reduces inflammation in a murine model of experimental colitis. BMC Biotechnol 2014; 14: 73, doi: 10.1186/1472-6750-14-73.

22. Philippidis P, Mason JC, Evans BJ, Nadra I, Taylor KM, Haskard DO, et al. Hemoglobin scavenger receptor CD163 mediates interleukin-10 release and heme oxygenase-1 synthesis: antiinflammatory monocyte-macrophage responses in vitro, in resolving skin blisters in vivo, and after cardiopulmonary bypass surgery. Circ Res 2004; 94: 119126, doi: 10.1161/01.RES.0000109414.78907.F9.

23. Schopfer FJ, Cipollina C, Freeman BA. Formation and signaling actions of electrophilic lipids. Chem Rev 2011; 111: 5997-6021, doi: 10.1021/cr200131e.

24. Bonacci G, Schopfer FJ, Batthyany Cl, Rudolph TK, Rudolph V, Khoo NK, et al. Electrophilic fatty acids regulate matrix metalloproteinase activity and expression. J Biol Chem 2011; 286: 16074-16081, doi: 10.1074/jbc.M111. 225029.

25. Tsikas D, Zoerner AA, Mitschke A, Gutzki FM. Nitro-fatty acids occur in human plasma in the picomolar range: a targeted nitro-lipidomics GC-MS/MS study. Lipids. 2009; 44: 855-865, doi: 10.1007/s11745-009-3332-4.

26. Douillard FP, O'Connell-Motherway M, Cambillau C, van Sinderen D. Expanding the molecular toolbox for Lactococcus lactis: construction of an inducible thioredoxin gene fusion expression system. Microb Cell Fact 2011; 10: 66, doi: 10.1186/1475-2859-10-66

27. Kang P, Toms D, Yin Y, Cheung Q, Gong J, De Lange K, et al. Epidermal growth factor-expressing Lactococcus lactis enhances intestinal development of early-weaned pigs. J Nutr 2010; 140: 806-811, doi: 10.3945/jn.109.114173.

28. Suttner DM, Sridhar K, Lee CS, Tomura T, Hansen TN, Dennery PA. Protective effects of transient HO-1 overexpression on susceptibility to oxygen toxicity in lung cells. Am J Physiol 1999; 276: L443-L451.

29. Bernbom N, Licht TR, Brogren $\mathrm{CH}$, Jelle $\mathrm{B}$, Johansen $\mathrm{AH}$, Badiola I, et al. Effects of Lactococcus lactis on composition of intestinal microbiota: role of nisin. Appl Environ Microbiol 2006; 72: 239-244, doi: 10.1128/AEM.72.1.239-244.2006. 